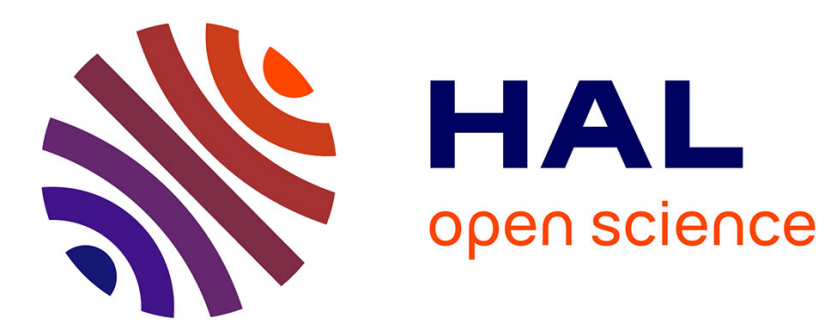

\title{
The organization of extended producer responsibility in waste policy with product differentiation
}

Pierre Fleckinger, Matthieu Glachant

\section{To cite this version:}

Pierre Fleckinger, Matthieu Glachant. The organization of extended producer responsibility in waste policy with product differentiation. Journal of Environmental Economics and Management, 2010, 59 (1), pp.57-66. 10.1016/j.jeem.2009.06.002 . hal-00446819

\section{HAL Id: hal-00446819}

https://hal-mines-paristech.archives-ouvertes.fr/hal-00446819

Submitted on 13 Jan 2010

HAL is a multi-disciplinary open access archive for the deposit and dissemination of scientific research documents, whether they are published or not. The documents may come from teaching and research institutions in France or abroad, or from public or private research centers.
L'archive ouverte pluridisciplinaire HAL, est destinée au dépôt et à la diffusion de documents scientifiques de niveau recherche, publiés ou non, émanant des établissements d'enseignement et de recherche français ou étrangers, des laboratoires publics ou privés. 


\title{
The Organization of Extended Producer Responsibility in Waste Policy with Product Differentiation
}

\author{
Pierre Fleckinger*, Matthieu Glachant ${ }^{\dagger}$
}

This version: February 2009

\begin{abstract}
The paper analyzes the efficiency of Extended Producer Responsibility (EPR) for waste management. We consider a vertically differentiated duopoly where endogenous market quality affects waste disposal costs. Each producer has to meet a take-back requirement that forces it to collect and treat the waste associated with its products. In line with reality, we assume that the producers can either organize themselves individually or cooperate by setting up a Producer Responsibility Organization (PRO). We study the various implementations of EPR. Central to the analysis is the trade-off between collusion made possible by the existence of a PRO and market power in the waste industry.
\end{abstract}

Key words: extended producer responsibility, waste policy, product differentiation JEL codes: L13, Q53

\footnotetext{
${ }^{*}$ University of Paris 1 \& Paris School of Economics. Email: pierre.fleckinger@univ-paris1.fr.

${ }^{\dagger}$ Corresponding author. Mines ParisTech, CERNA, 60 Boulevard Saint-Michel 75006 Paris. Email: glachant@ensmp.fr. Phone: + 33 140519229. Fax: +33 140519045.
} 


\section{Introduction}

An increasingly popular instrument for solving solid waste management problems is the Extended Producer Responsibility (EPR) program in which the Government assigns to producers the responsibility - financial and/or physical - for the treatment or disposal of their products at the end of life. It is expected that such programs could provide incentives to prevent waste at the source, promote environment-friendly product design, and support the achievement of public recycling and materials management goals. The seminal program in this respect is the German Green Dot scheme which was introduced in 1991 to deal with packaging waste. EPR now concerns a wide range of product groups and waste streams such as packaging, electrical appliances and electronics, batteries and accumulators, used oil, tires and end-of life vehicles in the European Union, Japan, South Korea, Canada, etc. The USA constitutes a noteworthy exception to this trend.

This paper develops a formal model of an Extended Producer Responsibility program. We analyze the welfare effects of this policy approach and the way a welfare-maximizing authority should regulate these programs.

In order to consider these issues with more precision, it is necessary to describe the key features of EPR programs in more detail [10]. The core of an EPR program is either a takeback requirement mandating individual producers to collect and treat the waste generated, or a legal obligation to finance these activities. In addition, the regulator frequently sets recycling objectives. Producers can implement individual solutions to fulfill their obligations. A possible example is the European Directive 2000/53/CE adopted in 2000 which requires car manufacturers to take back end-of-life vehicles free of charge. In most EU countries, each manufacturer has decided to launch its own program by contracting with car dismantlers and shredders.

However, bearing the responsibility individually is very costly for certain goods and products. Imagine the Coca Cola Company setting up a system on its own to deal with 
waste generated by its Coke cans and bottles. For these products, companies usually organize themselves collectively by creating a so-called Producer Responsibility Organization (PRO, hereafter). A PRO is a non-profit organization controlled by the producers, whose primary task is to set up and manage the infrastructures that organize the collection and processing of waste on behalf of their individual members. The salient example is the Duales System Deutschland (DSD) GmbH created under the Green Dot program.

The way in which individual producers finance the PRO is a crucial aspect of EPR design in that it directly influences the size of the incentives to prevent waste. The usual instrument consists of a fee per unit of product that each producer puts on the market. The product fee is frequently uniform across brands (e.g. $\$ 20$ per refrigerator). It can also take into account waste-related product characteristics. This is the case of packaging PROs like DSD, for which the fee rates vary across materials and depend on the weight and size of each packaging type. In this paper we consider both uniform fees and incentive fees which reward individual prevention efforts. ${ }^{1}$

Most importantly, the design of a specific EPR program is the result of producers' decisions. The very concept of EPR is based precisely on giving producers considerable freedom in the way they meet their obligations. This feature raises several efficiency questions. Is the assignment of an EPR to individual producers sufficient to obtain a socially efficient outcome? Or should regulators intervene in the producers' decisions to cooperate in a PRO? Should it regulate the way producers finance the PRO? More generally, do PROs allow for collusion? The paper addresses these questions.

We consider a duopoly in which each producer faces a take-back requirement that forces it to manage waste generated by the consumption of its products. In line with reality, we assume that the producer can either get organized individually or cooperate with others.

\footnotetext{
${ }^{1}$ The practicability of incentive fees varies across products. For instance, packaging is a simple good for which variable fees are relatively easy to implement for two reasons: the number of waste-related parameters is limited (packaging weight, size and type of materials) and these parameters are easy to monitor. For more complex goods - e.g. electrical appliances and electronics - incentive fees are more difficult to implement.
} 
Cooperation consists in setting up a Producer Responsibility Organization which collects and treats waste on behalf of producers. In a variant we also consider the possibility that producers contract out to waste management companies which have market power. We endogenize the producers' decisions with respect to the contribution schedule for financing PRO activities.

A crucial feature of the model is that products are differentiated. We have assumed so for the sake of realism: product differentiation is pervasive in real-world markets where EPR is implemented (cars, electrical appliances, food products, etc.). We also assume that market quality affects waste disposal costs. The quality has either a positive impact on waste management by reducing disposal costs - like product durability - or a negative impact when a high quality entails larger end-of-life costs, as in the case of sophisticated packaging. We also investigate the role of market power in the waste management industry.

We show that individual EPR generally fails to implement the first best optimum. Setting up a PRO presents an additional risk of collusion. In this regard, the analysis stresses the need to regulate the tariffs which finance the PRO activities. The paper provides useful guidelines for doing so.

The theoretical literature on extended responsibility programs is still very scarce. Strictly speaking, only Runkel [12] explicitly addresses EPR. Under perfect and imperfect competition, he analyzes the efficiency of several EPR instruments focusing on product durability. His paper's main contribution is to show how imperfect competition in the product market can damage the efficiency of EPR, due to the relationship between waste-related characteristics (product durability) and demand.

Our paper is more general. In a unified framework, we deal with cases where market quality is negatively correlated with waste disposal costs - like durability for durable goods - and with alternative situations where correlation is positive - like packaging complexity. We also extend Runkel's approach by endogenizing the design of EPR programs. In his setting, 
the EPR instruments are exogenous, meaning that they are not selected by producers facing an EPR obligation. By contrast, we see EPR as a mechanism of delegation of waste policies to producers. Accordingly, the core of our model is the evaluation of the impact of producers' decisions on the design of the EPR program. We are thus able to analyze collusion issues.

In Runkel's sense, many other papers deal with EPR instruments, namely exogenous upstream instruments targeting producers, such as recycling standards [11], a take-back requirement and various product taxes based on recyclability or waste content $[1,5,6,7$, $8,13]$. These papers analyze a wider spectrum of waste policy instruments than ours and compare their efficiency. However, they all assume perfect competition. In this regard, Runkel's work and ours show how imperfect competition has crucial implications for the results obtained.

Finally, the paper is also related to the literature on environmental product differentiation $[2,3,9]$. In this regard our main contribution is to focus on EPR specificities: collusion in the product market through the PRO or the impact of market power in downstream waste markets. But we discuss where necessary - in particular in Section 3 - how some of our results relate to this literature.

The remainder of the paper is structured as follows. In the next section we present the model. We then analyze the effect of introducing EPR when firms decide to assume their responsibility individually. In Section 4 we explore the PRO solution and compare it with individual EPR. Section 5 examines the impact of market power in the waste industry on individual programs. In Section 6 we extend the analysis of the PRO by introducing restrictions on the producers' contribution schedule. The last section is a conclusion. 


\section{The model}

We consider two producers of a consumption good that generates end of life waste. Both producers have to meet a take back requirement that forces them to bear the full cost of waste collection and disposal. They can either set up their own scheme to meet EPR obligations or cooperate by implementing a PRO. They can also differentiate the good to relax competition. The key here is the fact that the differentiation parameter - market quality - affects waste management costs. Most of our results are driven by the fact that this relationship leads EPR to influence firms' market strategy.

Why do we rely on a product differentiation model? Most previous papers on waste policy adopt a far more tractable setting of perfect competition. However, EPR essentially deals with household waste generated by the consumption of goods like cars, batteries and accumulators, packaged goods, etc. These products are purchased on markets where product differentiation is pervasive. Most importantly, the product characteristics that are differentiated (e.g. the durability of cars or white goods, the type of packaging) directly influence waste generation and waste management costs. As a result, the organization of EPR inevitably affects market competition. A product differentiation model is the appropriate tool to investigate this linkage.

We use a Mussa-Rosen vertical differentiation model in which the two producers engage in a two-stage game in which they set their quality first and then compete in prices. This type of model has already been used in an environmental policy context (see for instance [2] on eco-labelling). Producer $i$, with $i=1,2$, produces quality $\theta_{i}$ in quantity $q_{i}$. We assume that the quality $\theta_{i}$ is a binary variable with two possible values $\theta_{L}$ and $\theta_{H}\left(\right.$ with $\left.\theta_{L}<\theta_{H}\right) .^{2}$ Furthermore, a producer sells exactly one quality.

\footnotetext{
${ }^{2}$ Most previous papers assume that quality is a continuous variable and, for the sake of tractability, that the demand is inelastic so that consumers' choice is restricted to the brand's choice (e.g. [2]). In our model demand is elastic, so that meaningful results can be obtained, for a PRO may allow collusion. Quality is binary for tractability reasons.
} 
There is a continuum of consumers uniformly distributed on $[0,1]$. Each consumer is indexed by $x \in[0,1]$ and buys at most one unit, which generates utility $u(x, \theta, p)=\theta x-p$ when the price is $p$. Without loss of generality, we assume in the following that $\theta_{L}=1$ and $\theta_{H}=1+\delta$ with $\delta>0$, so that $\delta$ will be a measure of quality difference for the consumers. We now derive the demand for each quality when both coexist. Let $y$ denote the consumer who is indifferent between buying quality $L$ and quality $H$. The location of this consumer is determined by:

$$
u\left(y, \theta_{L}, p_{L}\right)=y-p_{L}=(1+\delta) y-p_{H}=u\left(y, \theta_{H}, p_{H}\right)
$$

Similarly, let $z$ denote the consumer who is indifferent between buying brand $L$ and buying nothing:

$$
u\left(z, \theta_{L}, p_{L}\right)=z-p_{L}=0
$$

As the number of consumers is normalized to one, the demand for the two different qualities is:

$$
\begin{gathered}
q_{L}=y-z=\frac{p_{H}-p_{L}}{\delta}-p_{L} \\
q_{H}=1-y=1-\frac{p_{H}-p_{L}}{\delta}
\end{gathered}
$$

When a single quality is marketed one also easily obtains the following demands, when only $\theta_{L}$ is present:

$$
q_{L}=1-p_{L}
$$

and when only $\theta_{H}$ is present:

$$
q_{H}=1-\frac{p_{H}}{1+\delta}
$$

Turning next to production costs, we assume a variable cost $c\left(\theta_{H}\right)=c$ for producing the 
high quality. Assuming a variable cost of quality sounds realistic, in so far as high quality products use more expensive materials and are more difficult to produce. Of course, they do also entail higher fixed costs of innovation, advertising, or design. But introducing a fixed cost in our setting poses a problem of tractability.

The variable cost for producing brand $\theta_{L}$ is assumed to be zero: $c\left(\theta_{L}\right)=0$, without any substantial loss of generality. In turn, we assume that the cost $c$ is sufficiently small so that, in the absence of environmental concerns, it would be valuable to produce high quality rather than low quality, at least for the consumer with the highest valuation:

\section{Assumption $1 c<\delta$}

The consumption of the good generates a social unit cost that depends on its quality, $w(\theta)$. This social cost of waste disposal and recycling ${ }^{3}$ is given by:

$$
\begin{gathered}
w\left(\theta_{L}\right)=w_{L} \\
w\left(\theta_{H}\right)=w_{H}
\end{gathered}
$$

We make the additional assumption that end-of-life costs are reasonable, so that at least the most demanding consumer is worth serving (both socially and in a market equilibrium):

\section{Assumption $2 w_{L}, w_{H}<1$}

Most importantly, we allow a higher market quality to be good either for the environment $\left(w_{L}>w_{H}\right)$ or bad $\left(w_{L} \leq w_{H}\right)$ in order to deal with different types of products and markets. This assumption contrasts with previous papers which, except for Runkel [12], assume no link between consumers' utility and the waste-related characteristics of the products (that

\footnotetext{
${ }^{3}$ We do not differentiate between waste disposal and waste recycling. This is because because we want to focus the analysis on upstream issues: firms' incentives to prevent waste and the impact of EPR on the product market.
} 
is $w_{L}=w_{H}$ ). To illustrate the relevance of our assumption, let us first consider durable goods such as refrigerators, tires, cars, or electronic equipment. For these goods, durability, reliability and reparability are parameters which matter in the competition process because they increase consumers' willingness to pay. They also affect waste production by reducing waste quantity and associated recycling and disposal costs by increasing the products' lifetime. This situation corresponds to $w_{L}>w_{H} \cdot{ }^{4}$

Alternatively, consider the food and beverage markets in which product differentiation often focuses on packaging characteristics: new bottle design, containers of different size, etc. In these markets, most consumers are ready to pay an extra premium for more sophisticated and complex packaging which often leads to higher waste management costs. This corresponds to the case $w_{L} \leq w_{H}$ in which market quality and waste management costs are positively correlated. One can also view this case as representing a market where green consumerism prevails, as consumers positively value environmental attributes of the product $^{5}$.

\subsection{Welfare optimum}

For further reference, we briefly go through the socially optimal configurations. Total welfare can conveniently be written as a function of $y$ and $z$ :

$$
\begin{aligned}
W(y, z) & =\int_{z}^{y} u\left(x, \theta_{L}, p_{L}\right) d x+\int_{y}^{1} u\left(x, \theta_{H}, p_{H}\right) d x+\left(p_{L}-w\left(\theta_{L}\right)\right) q_{L}-\left(p_{H}-c-w\left(\theta_{H}\right)\right) q_{H} \\
& =\frac{1}{2}\left(y^{2}-z^{2}\right)+\frac{1}{2}(1+\delta)\left(1-y^{2}\right)-w_{L}(y-z)-\left(c+w_{H}\right)(1-y)
\end{aligned}
$$

\footnotetext{
${ }^{4}$ As this primarily describes cases where higher quality products have a longer useful life, we could model this case using a discount factor. That is, $w$ would be the waste disposal cost of the low quality brand and $\rho w$ would be that of high quality brands (with $\rho$ a discount factor less than 1). But as we analyze in a unified framework the cases $w_{H}<w_{L}$ and $w_{H} \geq w_{L}$, it is more convenient to use more general notation.

${ }^{5}$ However, empirical evidence suggests that the effect of green consumerism is modest in practice (see for instance [4]). Accordingly, green consumerism is not a key concern in the rest of this paper.
} 
It is easy to obtain:

Lemma 1 The social optimum is such that:

- $q_{L}^{*}=1-w_{L}$ and $q_{H}^{*}=0$ if $w_{L}-w_{H} \leq-(\delta-c)$.

- $q_{L}^{*}=\frac{1}{\delta}\left(c-w_{L} \delta-\left(w_{L}-w_{H}\right)\right)$ and $q_{H}^{*}=\frac{1}{\delta}\left(\delta-c+w_{L}-w_{H}\right)$ if $-(\delta-c)<w_{L}-w_{H} \leq c-\delta w_{L}$.

- $q_{L}^{*}=0$ and $q_{H}^{*}=1-\frac{c+w_{H}}{1+\delta}$ if $c-\delta w_{L}<w_{L}-w_{H}$.

Proof. See the appendix.

This lemma is quite intuitive. For instance, the quantity $q_{L}^{*}$ decreases with the difference $w_{L}-w_{H}$. That is, the higher the waste cost of the low-quality product relative to the highquality product, the lower is its socially optimal quantity. Similarly, the higher the unit cost of producing high quality, $c$, the lower $q_{H}^{*}$ and the higher $q_{L}^{*}$. The parameter $\delta$, which reflects the difference in utility between the low and the high quality products, also has the expected impact: the higher $\delta$, the higher is $q_{H}^{*}$, and the lower is $q_{L}^{*}$.

\section{Individual EPR}

As noted in the introduction, producers can either manage their waste on their own or they can cooperate with others by setting up a PRO. We first consider individual EPR programs. In this case, each producer internalizes the cost of its own waste. As a result, its profit is:

$$
\pi_{i}=p_{i} q_{i}-\left(w\left(\theta_{i}\right)+c\left(\theta_{i}\right)\right) q_{i}
$$

It is important to note that individual EPR is in fact similar to a Pigovian tax. That is, a tax whose rate equals the marginal social damage $w(\theta)$. We shall discuss this point further below. 
Reasoning backward, we first solve for a Nash-Bertrand equilibrium in prices, given qualities $\theta_{1}$ and $\theta_{2}$. Three cases are possible: both firms produce low quality; both firms produce high quality; the products are differentiated. The analysis of the first two cases is straightforward: under Bertrand competition with homogenous goods, the producers set prices at marginal cost and make zero profits. Hence, we just need to identify the circumstances under which both producers derive positive profits, that is, when two qualities coexist in the market. Assuming an interior solution, it is routine to obtain:

$$
\begin{aligned}
q_{L}^{I} & =\frac{(1+\delta)\left(c-\delta w_{L}-\left(w_{L}-w_{H}\right)+\delta\left(1-w_{L}\right)\right)}{\delta(3+4 \delta)} \\
q_{H}^{I} & =\frac{(1+\delta)\left(2 \delta-c+w_{L}-w_{H}\right)-\delta\left(c+w_{H}\right)}{\delta(3+4 \delta)}
\end{aligned}
$$

The superscript $I$ indicates the market equilibrium under individual EPR. It is then straightforward to obtain:

$$
\begin{aligned}
\pi_{L}^{I} & =\frac{(1+\delta)\left[c-\delta w_{L}-\left(w_{L}-w_{H}\right)+\delta\left(1-w_{L}\right)\right]^{2}}{\delta(3+4 \delta)^{2}} \\
\pi_{H}^{I} & =\frac{\left[(1+\delta)\left(2 \delta-c+w_{L}-w_{H}\right)-\delta\left(c+w_{H}\right)\right]^{2}}{\delta(3+4 \delta)^{2}}
\end{aligned}
$$

These expressions for profits are valid whenever both quantities defined above are indeed positive. Otherwise the market is a non-differentiated Bertrand duopoly. We summarize these results in:

Lemma 2 Under an individual EPR program, the market outcome is as follows:

- $q_{L}^{I}=1-w_{L}$ and $q_{H}^{I}=0$ if $w_{L}-w_{H} \leq \Omega$.

- $q_{L}^{I}$ and $q_{H}^{I}$ are given respectively by (8) and (9) if $\Omega<w_{L}-w_{H} \leq \Phi$.

- $q_{L}^{I}=0$ and $q_{H}^{I}=1-\frac{c+w_{H}}{1+\delta}$ if $\Phi<w_{L}-w_{H}$. 
where

$$
\Omega \equiv-(\delta-c)-\delta\left(1-\frac{c+w_{H}}{1+\delta}\right) \text { and } \Phi \equiv c-\delta w_{L}+\delta\left(1-w_{L}\right)
$$

We can now compare the decentralized outcome under individual EPR with the social optimum. The different thresholds for $w_{L}-w_{H}$ found in Lemma 1 and Lemma 2 compare as:

$$
\Omega<-(\delta-c)<c-\delta w_{L}<\Phi
$$

Table 1 displays the social optimum with the different market outcomes as a function of the difference $w_{L}-w_{H} . H+L$ denotes a market structure where the two brands co-exist. $L$ and $H$ indicate a non-differentiated duopoly with quality $L$ and quality $H$, respectively.

\begin{tabular}{|c|c|c|c|c|c|}
\hline & 1 & 2 & 3 & 4 & 5 \\
\hline$w_{L}-w_{H}$ & $<\Omega$ & $\Omega \leq .<-(\delta-c)$ & $-(\delta-c) \leq .<c-\delta w_{L}$ & $c-\delta w_{L} \leq .<\Phi$ & $\Phi \leq$ \\
\hline Social optimum & & $L$ & $H+L$ & $H$ & \\
\hline Ind. EPR & $L$ & & $H+L$ & & $H$ \\
\hline
\end{tabular}

Table 1: Social optimum, and equilibrium under individual EPR

The table shows a standard result of the literature on production differentiation. Firms differentiate too much to relax competition, thereby extracting more surplus from consumers: under individual EPR, both brands coexist in the market in intervals 2-4 whereas product differentation is only socially optimal in interval 3 .

Another way of looking at these results is to remember that individual EPR is akin to a Pigovian tax. It is well known that a Pigovian tax is not socially optimal under imperfect competition as it does not correct for the market power distortions. In fact, when the difference in waste costs between the qualities $\left|w_{L}-w_{H}\right|$ is high enough (intervals 1 and 5 in Table 1), the individual organization of EPR - or a Pigovian tax - does a good job at 
eliminating dirty products. That is, high quality in interval 1, and low quality in interval 5. Thus, competition internalizing waste costs is sufficient in the two extreme cases.

But the incentives to differentiate are too strong in intermediate cases (intervals 2 and 4), and the "dirty" quality can survive in equilibrium. In other words, a Pigovian tax or individual EPR - is too lax to force exit of the socially non-desirable quality. This is in sharp contrast with models of imperfect competition with homogenous products where a Pigovian tax is classically too stringent compared to the optimal tax when accounting for market power.

Finally, in the middle interval 3, the market yields the right set of qualities $(H+L)$ but quantities are unduly restricted as differentiation entails market power. A Pigovian tax or individual EPR is now too stringent. Clearly, the relationship between the Pigovian tax rate and social welfare is not straightforward when products are differentiated (see [9], for further analysis).

Recall that a Pigovian tax is a specific corrective tax, the rate of which equals the marginal cost from waste disposal. Then, what are the differences between individual EPR and more general corrective taxes? The key is that the latter can be adjusted whereas the price signal generated by the former is given. This could suggest that EPR is socially less efficient than a corrective tax adjusted to mitigate the detrimental impacts of imperfect competition. Although the comparison of EPR with other instruments is clearly beyond the scope of this paper, it is worth mentioning that setting the appropriate tax rate is a complex task: we have seen above that, depending on the difference $w_{L}-w_{H}$, the rate should be reduced or increased relative to the Pigovian rate.

Before turning to the analysis of collective programs, it should be stressed that the equivalence between individual EPR and a Pigovian tax decisively hinges upon the assumption that producers bear the social cost of waste disposal. But, in practice, producers generally contract out to waste management companies. If waste firms have market power, producers 
will pay more than the waste disposal cost. In this respect, EPR is equivalent to a Pigovian tax in the extreme case where waste management is provided competitively. We examine the impact of market power in waste management on EPR in Section 5.

\section{Collective organization of EPR}

We now analyze the solution whereby producers set up a PRO to manage waste collectively. Let $T_{i}\left(q_{i}, \theta_{i}\right)$ denote the contribution schedule with which producers finance PRO activities. We assume here that producers are totally free to choose any contribution schedule. Accordingly, we do not impose any constraints on the tariff's design, that is, on the dependence of $T_{i}$ on $q_{i}$ and $\theta_{i}$. Contribution schedules can also differ among producers. Under these assumptions, the producers can implement any market outcome $\left(q_{i}, \theta_{i}\right)$. For instance, they can exclude one quality by selecting a tariff which is sufficiently costly for that quality.

This assumption captures the rationale of EPR which is to delegate waste management to producers. However, it also allows for full collusion. In practice, regulatory or technical constraints may limit the choice of tariffs. We shall discuss some of these constraints in Section 6.

From a market point of view, collusion obviously harms social welfare by unduly restricting quantities. But from an environmental point of view, things are less clear-cut as the market share of the dirty brand may decline. In order to explore this trade-off, we first characterize the market configuration.

The market outcomes are simply determined by the maximization of producers' joint profits. Assuming first that the two brands are sold, the producers maximize

$$
\max _{p_{L}, p_{H}} \pi^{C}=\left(p_{L}-w_{L}\right)\left(\frac{p_{H}-p_{L}}{\delta}-p_{L}\right)+\left(p_{H}-c-w_{H}\right)\left(1-\frac{p_{H}-p_{L}}{\delta}\right)
$$


Solving for the interior solution and substituting in (3) and (4) leads to

$$
q_{L}^{C}=\frac{c-\left(w_{L}-w_{H}\right)-\delta w_{L}}{2 \delta} \text { and } q_{H}^{C}=\frac{\delta-c+\left(w_{L}-w_{H}\right)}{2 \delta}
$$

which are both positive if and only if $-(\delta-c) \leq w_{L}-w_{H} \leq c-\delta w_{L}$. The equilibrium profit is then:

$$
\pi^{C}=\frac{\left(\delta-c-\left(w_{L}-w_{H}\right)\right)^{2}+\delta\left(1-w_{L}\right)^{2}}{4 \delta}
$$

The maximization program in the other two cases - in which only one quality is chosen in equilibrium - is simply that of the corresponding monopoly. This leads to:

Lemma 3 A collective EPR program induces the following market outcomes:

1. $q_{L}^{C}=\left(1-w_{L}\right) / 2$ and $q_{H}^{*}=0$ if $w_{L}-w_{H} \leq-(\delta-c)$.

2. $q_{L}^{C}=\frac{1}{2 \delta}\left(c-w_{L} \delta-\left(w_{L}-w_{H}\right)\right)$ and $q_{H}^{C}=\frac{1}{2 \delta}\left(\delta-c+w_{L}-w_{H}\right)$ if $-(\delta-c)<w_{L}-w_{H} \leq$ $c-\delta w_{L}$

3. $q_{L}^{C}=0$ and $q_{H}^{C}=\frac{1+\delta-c-w_{H}}{2(1+\delta)}$ if $c-\delta w_{L}<w_{L}-w_{H}$.

This lemma presents surprising similarities with Lemma 1 which describes the social optimum. In particular, the conditions on $w_{L}-w_{H}$ which determine the different market outcomes are the same as that of Lemma 1: the perfectly collusive PRO does not overdifferentiate products. The only difference is that quantities are smaller. Specifically, we have $q_{L}^{C}=q_{L}^{*} / 2$ and $q_{H}^{C}=q_{H}^{*} / 2$. This is the expected effect that collusion leads to reduced output levels.

In contrast with individual EPR, why do the firms not over-differentiate products? Under individual EPR, over-differentiation is the only way for the producers to obtain market power. Under collective EPR, firms have market power from the outset. As a result, overdifferentiation is useless, as it can directly restrict quantities. 
This suggests that the social welfare ranking between individual EPR and the PRO solution might be ambiguous. On the negative side, the PRO restricts quantities. But on the positive side, it provides the right set of brands in the market. We show in the Appendix that the former effect always dominates the latter so that:

Proposition 1 A PRO functioning under completely collusive behavior is socially less desirable than individual EPR.

Proof. See Appendix.

One needs to be cautious when deriving policy implications from this proposition. In the real world, gathering several producers in a single organization frequently yields advantages that have not been integrated into our analysis so far. For instance, setting up a PRO lowers monitoring and enforcement costs borne by the regulatory agency in charge of EPR implementation. Most importantly, a PRO can exploit economies of scope or economies of scale in waste management.

The proposition essentially highlights the need to regulate PRO tariffs. As it reduces output too much, regulations should seek to reduce the price signal delivered by the incentive fee. In Section 6, we explore one way of doing so: the use of uniform tariffs which do not differentiate contributions across brands.

\section{Market power in the waste industry}

In practice, producers do not manage their waste directly. Both PROs and firms under individual EPR contract out to traditional waste management companies or municipalities for different services: separate collection, waste disposal, recycling, etc.

Our model may be compatible with a view where a PRO or individual producers entirely delegate waste management to an independent firm and pay the exact costs of their end-of- 
life products $\left(w_{L}\right.$ or $\left.w_{H}\right)$. By doing so, we simply assume that waste services are provided competitively.

It is well-known that the existence of economies of scale and transportation costs in waste management gives market power to waste firms or even leads to geographic monopolies under certain circumstances. Arguably, this primarily hurts producers that assume their responsibility individually, whereas cooperation in PROs helps counterbalance this power or even enables firms to partly integrate certain waste management activities. In this section, we explore the consequence of this asymmetry between collective and individual programs.

We do so by introducing the assumption that producers pay the monopoly price under individual EPR, whereas the PRO obtains the competitive price. We are aware that the real world is not so clear-cut, but this hypothesis allows us to sharply contrast the two regimes.

Under this assumption, Lemma 3, which describes the PRO regime, is still valid. Therefore, we just need to analyze individual programs. We assume that the waste firm can discriminate producers and uses linear pricing. Formally, producers pay $x_{L}$ and $x_{H}$ per unit of products $L$ and $H$ sold in the market ${ }^{6}$.

The fact that the waste firm relies on linear pricing has important implications. A general pricing schedule would allow the waste monopolist to entirely reap producers' market surplus. The waste firm would therefore select the prices which implement (indirectly) the collusive equilibrium given by Lemma 3. As a result, individual EPR and the perfectly collusive PRO would be strictly equivalent. Imposing a constraint on the tariff is a way to capture the fact that the downstream waste firm has less influence on the product market than the producers. ${ }^{7}$ In this regard, linear pricing is the most realistic restriction to achieve this.

Of course we can anticipate that market power in waste markets harms social welfare as

\footnotetext{
${ }^{6}$ Implicitly, this means that the quantity of waste generated is proportional to the quantity of products, $q_{L}$ or $q_{H}$.

${ }^{7}$ It should be stressed that our results do not depend on the assumption of linear pricing. Any limits to the full extraction of surplus by the (downstream) waste treatment sector would generate the very same insights.
} 
compared to individual EPR with a competitive supply of waste management, as it generates a problem of double-marginalization: the accumulated market power of the producers and that of the waste management firm.

We now start the formal analysis. The waste management firm maximizes:

$$
\Gamma\left(x_{L}, x_{H}\right) \equiv\left(x_{L}-w_{L}\right) q_{L}\left(x_{L}, x_{H}\right)+\left(x_{H}-w_{H}\right) q_{H}\left(x_{L}, x_{H}\right)
$$

where $q_{L}\left(x_{L}, x_{H}\right)$ and $q_{H}\left(x_{L}, x_{H}\right)$ are the resulting quantities in the game between the firms when they face the pair of waste prices $\left(x_{L}, x_{H}\right)$. The solution of this program is quite straightforward and is summarized in the following:

Lemma 4 The waste management firm selects the following prices:

1. $x_{L}=\frac{1+w_{L}}{2}$ and $x_{H}=\frac{1+\delta-c+w_{H}}{2}$ if it wants to implement a differentiated duopoly. This leads to the quantities $q_{L}^{m}=q_{L}^{I} / 2$ and $q_{H}^{m}=q_{H}^{I} / 2$ where the superscript $m$ denotes individual EPR with market power.

2. $x_{L}=\frac{1+w_{L}}{2}, x_{H}=+\infty$ for a non-differentiated duopoly with brand $L$. In this case, we obtain the collusive quantity $q_{L}^{m}=q_{L}^{C}$ where $q_{L}^{C}$ is defined in Lemma 3 (case 2).

3. $x_{L}=+\infty, x_{H}=\frac{\delta-c+w_{H}}{2}$ for a non-differentiated duopoly with brand $H$ with the monopoly quantity $q_{H}^{m}=q_{H}^{C}$ defined in Lemma 3 (case 3).

\section{Proof. See Appendix.}

We are now able to compare the welfare properties of this individual EPR program with the (perfectly collusive) PRO. The two regimes are obviously equivalent when they both implement the monopoly outcome with homogeneous products.

When the market structure is a differentiated duopoly, the perfectly collusive PRO clearly outperforms individual programs: quantities are reduced by exactly half under individual 
EPR relative to the competitive scenario, whereas quantities are reduced by half with the PRO but relative to the first best quantities $q_{L}^{*}$ and $q_{H}^{*}$. Hence, $q_{L}^{m}<q_{L}^{C}$ and $q_{H}^{m}<q_{H}^{C}$. This is a specific illustration of the general result that double-marginalization hurts social welfare.

Moreover, while the waste firm reaps all the profit in the case of a homogenous duopoly, it captures only a fraction of the surplus in the case of a differentiated duopoly, since firms are able to make profits. Therefore, the homogenous duopoly is relatively more attractive for the waste firm which accordingly implements it more often than a collusive PRO would.

The following summarizes these results:

Proposition 2 A perfectly collusive PRO is socially more desirable than an individual EPR program where individual firms face a monopolist in the waste market.

We have analyzed individual EPR with two polar cases of market power in the waste industry: the competitive case in Section 3 and the monopoly case here. ${ }^{8}$ From this analysis, the collusive PRO lies somewhere in between in terms of welfare. It may be (socially) preferred to individual programs if the market power of the waste firm is too high. In other words, collusive behavior made possible by the PRO has to be traded-off against the double-marginalization effect arising under individual EPR.

Finally, note that we have contrasted individual and collective EPR in terms of market power. Instead, we could have done so in terms of vertical integration: there are reasons to suppose that a PRO is more likely to integrate certain waste management activities than individual producers would. This alternative hypothesis would yield the same result, as the overall tradeoff is identical: market power in the product market versus double marginalization under individual EPR.

\footnotetext{
${ }^{8}$ It is a straightforward exercise to study the intermediate cases. For example, one could introduce bargaining power between (upstream) producers and (downstream) waste treatment firms, or Cournot competition among downstream firms, making their number vary between 1 and infinity. For our purpose, it is enough to reason with the extreme cases and to invoke continuity to tackle the intermediate case.
} 


\section{Collective EPR with uniform linear tariffs}

We complete the analysis of collective EPR in this section by introducing restrictions on tariffs. In Section 4 we assumed that the PRO contribution schedule can implement any market outcome. In practice, this requires discrimination between different qualities. But real-world PROs frequently implement tariffs that are uniform in quality and linear in quantity - say $\$ 20$ per refrigerator, irrespective of its waste management cost [10]. Possible illustrations are electrical appliances, or electronics. For these complex products, the parameters influencing the waste disposal of a given brand - durability, dismantling ability, recyclability - are so numerous that incentive tariffs may be too costly to implement.

In policy circles, uniform and linear tariffs are frequently criticized as they fail to provide producers with incentives to reduce waste at source. Nevertheless linearity and uniformity also hinder collusion. In this section, we analyze the welfare properties of PROs using linear and uniform tariffs and compare them with the perfectly-collusive PRO. The underlying objective is to investigate whether regulators should force PROs to rely on incentive tariffs.

We consider a linear tariff whereby each producer pays a fee $\beta$ per unit of product put on the market. We will endogenously determine the fee $\beta$ that will be adopted by the producers. To do so, we first need to characterize the relation between the quantities $q_{L}$ and $q_{H}$ and $\beta$. Formally, assuming that both brands are marketed, the two producers who pay $\beta$ per unit of product solve:

$$
\begin{aligned}
& \max _{p_{L}} \pi_{L}=\left(p_{L}-\beta\right)\left(\frac{p_{H}-p_{L}}{\delta}-p_{L}\right) \\
& \max _{p_{H}} \pi_{H}=\left(p_{H}-\beta-c\right)\left(1-\frac{p_{H}-p_{L}}{\delta}\right)
\end{aligned}
$$

As usual, we derive the first order conditions and do the appropriate substitutions leading 
to the quantities contingent on $\beta$ :

$$
\begin{aligned}
q_{L}(\beta) & =\frac{(1+\delta)(\delta+c-2 \delta \beta)}{\delta(3+4 \delta)} \\
q_{H}(\beta) & =\frac{2 \delta(1+\delta)-c(1+2 \delta)-\delta \beta}{\delta(3+4 \delta)}
\end{aligned}
$$

Note that $q_{L}(\beta)>0$ requires $\beta<(c+\delta) / 2 \delta$ while $q_{H}(\beta)>0$ requires $\beta<[2 \delta(1+\delta)-$ $c(1+2 \delta)] / \delta$. Moreover, $(c+\delta) / 2 \delta<[2 \delta(1+\delta)-c(1+2 \delta)] / \delta$ as $c<\delta$. This means that only two market configurations are feasible: when $\beta<(c+\delta) / 2 \delta$, the linear tariff induces a differentiated duopoly; when $\beta$ is higher, $q_{L}(\beta)=0$ and the firms sell only the high quality brand. ${ }^{9}$

Moving backward, the tariff rate that will emerge in equilibrium is the solution to

$$
\max _{\beta} \Pi^{U} \equiv \pi_{L}(\beta)+\pi_{H}(\beta)+\beta\left[q_{L}(\beta)+q_{H}(\beta)\right]-w_{L} q_{L}(\beta)-w_{H} q_{H}(\beta)
$$

under the constraint $\beta<(c+\delta) / 2 \delta$. The joint profit with uniform and linear pricing is the sum of market profits plus the PRO revenue $\beta\left[q_{L}(\beta)+q_{H}(\beta)\right]$ minus the total waste disposal cost $w_{L} q_{L}(\beta)+w_{H} q_{H}(\beta)$. The solution is derived in the appendix. It yields:

Lemma 5 A PRO using a uniform linear tariff leads to

- a differentiated duopoly if $w_{L}-w_{H} \in\left(\min \left\{r_{1}, r_{2}\right\}, \max \left\{r_{1}, r_{2}\right\}\right)$ with

$$
\begin{aligned}
& r_{1}=-\left(c-\delta w_{L}\right) \frac{(1+\delta) \sqrt{4 \delta+9}+(\delta+3)}{2 \delta(\delta+2)} \\
& r_{2}=\left(c-\delta w_{L}\right) \frac{(1+\delta) \sqrt{4 \delta+9}-(\delta+3)}{2 \delta(\delta+2)}
\end{aligned}
$$

in which case, the equilibrium quantities are $q_{L}(\hat{\beta})$ and $q_{H}(\hat{\beta})$ where $\hat{\beta}$ is defined by $d \Pi^{U} / d \beta=0$.

\footnotetext{
${ }^{9}$ Note that linearity of tariffs is no hindrance to collusion, so long as the rate can differ between low- and high-quality products as the PRO can get any pair $\left(q_{L}, q_{H}\right)$ by setting appropriate brand-specific rates.
} 
- or else a high quality duopoly with the quantity $q_{H}^{C}$ defined in Lemma 3.

Proof. See the Appendix.

The most important message of the lemma is that the PRO never implements a nondifferentiated duopoly with the low-quality brand. This is just not feasible with a uniform tariff: when $\beta$ increases, the low-quality brand is the first to exit the market as its utility for consumers is less than its cost advantage (recall that $c<\delta$ ).

Note that the firms unsurprisingly prefer a market with only high-quality products when the low-quality brand is dirtier $\left(w_{L}>w_{H}\right)^{10}$. But the fact that the same is true in the opposite case where $w_{L}<w_{H}^{11}$ is much less intuitive. Although the high quality brand induces higher costs of waste disposal, the PRO adopts a tariff which leads to the exit of the cleaner brand $L$. But it does so here because increasing $\beta$ is the only way to reduce sufficiently the quantity of brand $H$ and the related disposal cost.

Turning next to welfare considerations, we compute equilibrium quantities by substituting $\hat{\beta}$ in (11) and (12) and plug them in (7). Mathematical expressions of welfare are complex, but we show in the appendix that

Proposition 3 A PRO with uniform and linear pricing is socially preferable to the perfectly collusive PRO when $c-\delta w_{L}>0$ and $w_{L}-w_{H} \in\left(\max \left\{r_{2}, r_{3}\right\}, r_{4}\right)$ with

$$
\begin{aligned}
& r_{2}=\left(c-\delta w_{L}\right) \frac{(1+\delta) \sqrt{4 \delta+9}-(\delta+3)}{2 \delta(\delta+2)}<0 \\
& r_{3}=\frac{4(1+\delta)(\delta-c)-3\left(c-\delta w_{L}\right)}{3(3+2 \delta)}<0 \\
& r_{4}=\frac{c-\delta w_{L}}{3+2 \delta}>0
\end{aligned}
$$

In this case, the two PROs implement a differentiated duopoly.

\footnotetext{
${ }^{10}$ This is so because $w_{L}-w_{H}>\max \left\{r_{1}, r_{2}\right\}$ implies $w_{L}-w_{H}>0$ as $\max \left\{r_{1}, r_{2}\right\}>0$.

${ }^{11}$ As $w_{L}-w_{H}<\min \left\{r_{1}, r_{2}\right\}<0$
} 
Proof. See the Appendix.

The interpretation of the conditions $w_{L}-w_{H} \in\left(\max \left\{r_{2}, r_{3}\right\}, r_{4}\right)$ and $c-\delta w_{L}>0$ allows us to write a corollary which facilitates the discussion of these results:

Corollary 1 Uniform and linear pricing improves social welfare when 1) the two brands are not too different in terms of production cost (as reflected by c), utility for consumers (as reflected by $\delta$ ) and end-of-life costs (as reflected by the difference $\left|w_{L}-w_{H}\right|$ ) and when 2) the waste disposal cost is not too high (as reflected by $w_{L}$ ).

This corollary is very intuitive. Uniform and linear pricing is a "one size fits all" approach. This logically harms welfare when products are particularly heterogeneous. It is moreover not surprising that the efficiency loss increases when waste disposal costs are high; that is, when waste management is an important issue for the products covered by the EPR program.

\section{Conclusion}

This paper develops a model of product differentiation to analyze the welfare properties of Extended Producer Responsibility programs. In particular, we allow waste costs and product quality to be positively or negatively correlated.

We show that the assignment of extended producer responsibility is clearly not sufficient to ensure an efficient producer response. If waste management is competitively supplied, programs where firms undertake their responsibility individually are very similar to a Pigovian tax, as each producer bears the social cost of its own waste. It is therefore not surprising that they fail to implement the first best optimum as competition is imperfect in the product market. Collective programs, whereby producers delegate their responsibility to a PRO raise collusion concerns.

Public authorities should therefore regulate EPR. We have started to investigate how this should be done. More precisely, we have addressed two questions: first, should the regulator 
encourage individual or collective programs? Second, in the case of collective programs, should it force the PRO to use incentive tariffs which differentiate contributions according to waste-related characteristics, or tariffs that are uniform across brands ?

As for the first question, our analysis highlights a tradeoff between collusion in the product market through the PRO and market power in the downstream waste market, which may asymmetrically hurt producers opting for individual EPR. We show that individual EPR always yields a higher welfare than a perfectly collusive PRO if waste management is competitively supplied.

But in the opposite case where individual EPR leads producers to pay the monopoly price for waste management, perfect collusion under collective EPR is socially preferable. Indeed the pricing by the (downstream) waste treatment firm distorts the product market outcome more than maximal collusion between producers does.

Turning next to PRO tariffs, we explore the tradeoff between incentive tariffs - which enable full collusion in the product market -, and uniform tariffs - which fail to internalize brand-specific waste disposal costs. We show that uniform and linear pricing improves social welfare as compared to the perfectly collusive PRO when products are not too different in terms of production cost, market quality and waste disposal costs, and when the absolute level of waste disposal cost is not too high.

Extensive research is clearly still required on regulation issues. Combining EPR with corrective taxes to reduce distortions in the product market might improve social welfare. But we should keep in mind that too intrusive regulations would contradict the essence of EPR which is delegation. Finally, the comparison of EPR with other waste policy instruments (for example, product taxes, unit-based pricing) remains to be drawn. 


\section{Acknowledgements}

The financial support of the French Ministry of the Environment is acknowledged. We also thank the editor, and two anonymous reviewers for their generous help and useful comments. Finally we are particularly grateful to Howard Chang whose comments led us to revise very significantly an earlier version of the paper. 


\section{References}

[1] R.F.T. Aalbers and H.R.J. Vollebergh, An economic analysis of mixing wastes, Environ. Resource Econ. 39, 311-330 (2006).

[2] G.S. Amacher , E. Koskela and M. Ollikainen, Environmental quality competition and eco-labelling, J. Environ. Econom. Management 47, 284-306 (2004).

[3] S. Arora, and S. Gangopadhyay (1995) Toward a theoretical model of voluntary overcompliance, J. Econ. Behav. Organ., 28(3), 289-309.

[4] T.B. Bjørner, L.G. Hansen and C.S. Russell, Environmental labeling and consumers' choice-an empirical analysis of the effect of the Nordic Swan, J. Environ. Econom. Management 47, 411-434 (2004).

[5] P. Calcott and M. Walls, Can downstream waste disposal policies encourage upstream "Design for the Environment"?, Amer. Econ. Rev. Papers and Proceedings 90, 233-237 (2000).

[6] C. Choe and I. Fraser, An economic analysis of household waste management, J. Environ. Econom. Management 38, 234-246 (1999).

[7] T. Eichner and R. Pethig, Product design and efficient management of recycling and waste treatment, J. Environ. Econom. Management 41, 109-134 (2001).

[8] D. Fullerton and W. Wu, Policies for green design, J. Environ. Econom. Management 36, 131-148 (1998).

[9] C. Lombardini-Riipinen, Optimal tax policy under environmental quality competition, Environ. Resource Econ. , 32, 317-336 (2005).

[10] OECD, Economic Aspects of Extended Producer Responsibility, OECD publishing, Paris (2004). 
[11] K. Palmer and M. Walls, Optimal policies for solid waste disposal: taxes subsidies, and standards, J. Public Econ. 65, 193-205 (1997).

[12] M. Runkel, Product durability and Extended Producer Responsibility in solid waste management, Environ. Resource Econ. 24, 161-182 (2003).

[13] T. Shinkuma, On the second-best policy of household's waste recycling, Environ. Resource Econ. 24, 77-95 (2003).

\section{Appendix}

\subsection{Proof of Lemma 1}

The social welfare function is strictly concave in $(y, z)$, the first order conditions are:

$$
\begin{array}{r}
-\delta y+c-\left(w_{L}-w_{H}\right)=0 \\
-z+w_{L}=0
\end{array}
$$

and the feasible domain is $0 \leq z \leq y \leq 1$. The optimum is thus at: $\left(y^{*}=\frac{c-\left(w_{L}-w_{H}\right)}{\delta}, z^{*}=w_{L}\right)$ for an interior solution, and at $y^{*}=1$ or $y^{*}=z^{*}$ for corner solutions (clearly, $z^{*}=0$ cannot happen for positive costs). It follows from (3) and (4) that $q_{L}^{*}=y^{*}-z^{*}>0$ if $w_{L}-w_{H} \leq c-\delta w_{L}$ and $q_{H}^{*}=1-y^{*}>0$ if $w_{L}-w_{H} \geq-(\delta-c)$. Both conditions can be satisfied simultaneously, which yields the interior solution, i.e. the second case of the lemma. When either one fails, we have a single quality at the social optimum. When $q_{L}^{*}=y^{*}-z^{*}=0$, $W=\frac{1}{2}(1+\delta)\left(1-y^{2}\right)-\left(c+w_{L}\right)(1-y)$. Differentiating $W$, we obtain $y^{*}=\left(c+w_{L}\right) /(1+\delta)$. Alternatively, when $w_{L}-w_{H} \leq-(\delta-c)$ the high quality is not valuable in relative terms, even for the most demanding consumer $(x=1)$, so that $q_{H}^{*}=0$ and $z^{*}=w_{L}$. 


\subsection{Proof of Proposition 1}

There are five cases to consider, referring to Table 1 (recall that the thresholds in terms of $w_{L}-w_{H}$ are the same as in the first-best case, but the quantities are half). In the two extreme cases, 1 and 5, an individual firm induces Bertrand competition on the first-best quality, so that it performs strictly better than (perfectly collusive) collective EPR. We study the intermediate cases in turn.

Case 3. From the previous results, we know that:

$$
q_{H}^{I}=\frac{(1+\delta)\left(2 \delta-c+w_{L}-w_{H}\right)-\delta\left(c+w_{H}\right)}{\delta(3+4 \delta)} \text { and } q_{H}^{C}=\frac{\delta-c+\left(w_{L}-w_{H}\right)}{2 \delta}
$$

so that

$$
q_{H}^{I}-q_{H}^{C}=\frac{c-\delta w_{L}-\left(w_{L}-w_{H}\right)+\delta\left(1-w_{L}\right)}{2 \delta(3+4 \delta)}
$$

which is positive since $\left(w_{L}-w_{H}\right) \leq c-\delta w_{L}$ in this case, and $w_{L} \leq 1$. We also know that

$$
q_{L}^{I}-q_{L}^{C}=\frac{(1+2 \delta)\left(w_{L}-w_{H}+\delta-c\right)+\delta\left(1-w_{L}\right)}{2 \delta(3+4 \delta)}
$$

which is positive since $\left(w_{L}-w_{H}\right) \geq-(\delta-c)$, and $w_{L} \leq 1$. Quantities under individual EPR are thus always closer to first best quantities.

Case 2. In this case,

$$
q_{L}^{C}=\frac{1-w_{L}}{2} \text { and } q_{L}^{I}=\frac{(1+\delta)\left(c-\delta w_{L}-\left(w_{L}-w_{H}\right)+\delta\left(1-w_{L}\right)\right)}{\delta(3+4 \delta)}
$$

so that

$$
q_{L}^{I}-q_{L}^{C}=\frac{(1+2 \delta)\left(-(\delta-c)-\left(w_{L}-w_{H}\right)\right)+c-\delta w_{L}-\left(w_{L}-w_{H}\right)}{2 \delta(3+4 \delta)}
$$

which is positive from the thresholds on $w_{L}-w_{H}$. 
Case 4. Here:

$$
q_{H}^{I}=\frac{(1+\delta)\left(2 \delta-c+w_{L}-w_{H}\right)-\delta\left(c+w_{H}\right)}{\delta(3+4 \delta)} \text { and } q_{H}^{C}=\frac{1+\delta-c-w_{H}}{2(1+\delta)}
$$

Hence

$$
q_{H}^{I}-q_{H}^{C}=\frac{-\left(w_{L}-w_{H}\right)+c-\delta w_{L}+\delta\left(1-w_{L}\right)}{2 \delta(3+4 \delta)}
$$

which is positive since in that region $w_{L}-w_{H}<\Phi=c-\delta w_{L}+\delta\left(1-w_{L}\right)$.

Overall, for all cases, at least one quantity is higher under individual EPR, implying that individual EPR always performs better than a perfectly collusive PRO.

\subsection{Proof of Lemma 4}

Cases 2 and 3 are straightforward. When the waste firm implements a (Bertrand) duopoly with identical products, the producers charge a price equal to marginal cost and make zero profits in equilibrium. The waste firm can thus set the prices $x_{L}$ and $x_{H}$ leading to the monopoly quantity defined in Lemma 3 (cases 2 and 3 ) so that $q_{L}^{m}=q_{L}^{C}$ and $q_{H}^{m}=q_{H}^{C}$. The expressions for $x_{L}$ and $x_{H}$ are obtained by substituting $q_{L}^{m}$ and $q_{H}^{m}$ in (5) and (6) and rearranging. The price for the alternative brand is set high enough to discourage its production.

In case 1 , the equilibrium quantity for given $x_{L}$ and $x_{H}$ are formally identical to the case of independent EPR except that $x_{L}$ and $x_{H}$ replace $w_{L}$ and $w_{H}$. Substituting these values in (10) leads to a concave function of $\left(x_{L}, x_{H}\right)$ for the interior solution:

$$
\begin{aligned}
& \left(x_{L}-w_{L}\right) \frac{(1+\delta)\left(c-\delta x_{L}-\left(x_{L}-x_{H}\right)+\delta\left(1-x_{L}\right)\right)}{\delta(3+4 \delta)} \\
& +\left(x_{H}-w_{H}\right) \frac{(1+\delta)\left(2 \delta-c+x_{L}-x_{H}\right)-\delta\left(c+x_{H}\right)}{\delta(3+4 \delta)}
\end{aligned}
$$

Routine calculations show that the waste firm chooses the pair of prices stated in the lemma. 


\subsection{Proof of Lemma 5}

Let $\Pi^{U}$ denote the joint profit. We need to solve

$$
\max _{\beta} \Pi^{U} \equiv \pi_{L}(\beta)+\pi_{H}(\beta)+\beta\left[q_{L}(\beta)+q_{H}(\beta)\right]-w_{L} q_{L}(\beta)-w_{H} q_{H}(\beta)
$$

subject to

$$
\beta<(c+\delta) / 2 \delta
$$

To begin, calculations shows that $d^{2} \Pi^{U} / d \beta^{2}<0$. We then differentiate $\Pi^{U}$ and solve for $\beta$, leading to

$$
\hat{\beta}=\frac{1}{2}+\frac{(3+4 \delta)(3+2 \delta) w_{L}-(3+4 \delta)\left(w_{L}-w_{H}\right)-c(5+4 \delta)}{2(1+\delta)(9+4 \delta)}
$$

$\hat{\beta}$ clearly satisfies (13) if

$$
w_{L}-w_{H}>-(3+2 \delta)\left(c-\delta w_{L}\right) / \delta
$$

Now, we study whether this configuration is jointly more profitable for the firms than the implementation of the duopoly with the high-quality brand. Quantities in the latter case correspond to the monopoly quantities given in Case 3 of Lemma 3. Calculations show that the difference in equilibrium profits $\Pi^{U}(\hat{\beta})-\Pi^{C}$ has the same sign as that of

$$
A\left(w_{L}-w_{H}\right)^{2}+B\left(w_{L}-w_{H}\right)+C
$$


with $A=-\delta,=B-(\delta+3)\left(c-\delta w_{L}\right)$ and $C=(\delta+2)\left(c-\delta w_{L}\right)^{2}$. This polynomial has two roots

$$
\begin{aligned}
& r_{1}=\left(c-\delta w_{L}\right) \frac{(1+\delta) \sqrt{4 \delta+9}-(\delta+3)}{2 \delta(\delta+2)} \\
& r_{2}=-\left(c-\delta w_{L}\right) \frac{(1+\delta) \sqrt{4 \delta+9}+(\delta+3)}{2 \delta(\delta+2)}
\end{aligned}
$$

We then consider two cases:

- If $c-\delta w_{L} \leq 0$,we have $r_{1}<0$ and $r_{2}>0$. From $C>0$ it follows that $\Pi^{U}>\Pi^{C}$ if $\left(w_{L}-w_{H}\right) \in\left(r_{1}, r_{2}\right)$. This is compatible with the feasibility condition (14) as $r_{2}<-(3+2 \delta)\left(c-\delta w_{L}\right) / \delta$. Hence the differentiated duopoly arises in the interval $\left(r_{1}, r_{2}\right)$.

- If $c-\delta w_{L}>0, r_{1}>0$ and $r_{2}<0$, meaning that $\Pi^{U}>\Pi^{C}$ if $\left(w_{L}-w_{H}\right) \in\left(r_{2}, r_{1}\right)$. And this condition is binding as $-(3+2 \delta)\left(c-\delta w_{L}\right) / \delta<r_{2}$.

\subsection{Proof Proposition 3}

Recall that the threshold values for $w_{L}-w_{H}$ which determines the different outcomes under EPR are $-(\delta-c)$ and $c-\delta w_{L}$ while, under uniform pricing, they are $r_{1}$ and $r_{2}$. It is then easy to show that

$$
\begin{gathered}
-(d-c)<c-\delta w_{L}<r_{1}<r_{2} \text { if } c<\delta w_{L} \\
-(d-c)<r_{2}<r_{1} \leq c-\delta w_{L} \text { if } \delta w_{L} \leq c<c_{0} \\
r_{2} \leq-(d-c)<r_{1}<c-\delta w_{L} \text { if } c_{0} \leq c<\delta
\end{gathered}
$$

with

$$
c_{0}=\frac{\delta w_{L}(\delta+3+(1+\delta) \sqrt{4 \delta+9})+2 \delta^{2}(\delta+2)}{(1+\delta)(2 \delta+3+\sqrt{4 \delta+9})}
$$


We consider these three cases in turn.

$\mathbf{A} c<\delta w_{L}$

We have $-(\delta-c)<c-\delta w_{L}<r_{1}<r_{2}$. We analyze successively the different intervals for $w_{L}-w_{H}$

A1 $w_{L}-w_{H}<-(\delta-c)$. Under perfect collusion, we obtain a non-differentiated market with brand $L$ with the quantity $q_{L}^{C}=\left(1-w_{L}\right) / 2$. With uniform and linear pricing, the market is also not differentiated but with brand $H$ in quantity $q_{H}^{C}=\frac{1+\delta-c-w_{H}}{2(1+\delta)}$. As the socially optimal quantities are $q_{L}^{*}=2 q_{H}^{C}$ and $q_{H}^{*}=0$, the collusive PRO dominates the PRO using uniform and linear pricing because $q_{H}^{C}<q_{L}^{C}<q_{L}^{*}$.

A2 $-(\delta-c)<w_{L}-w_{H}<c-\delta w_{L}$. Linear pricing still induces a market with brand $H$ while the perfectly collusive PRO induces the differentiated duopoly. Straightforward calculations yield

$$
W^{U}-W^{C}=-\frac{3\left(c-(1+\delta) w_{L}+w_{H}\right)^{2}}{8(1+\delta) \delta}<0
$$

A3 $c-\delta w_{L}<w_{L}-w_{H}<r_{1}$. The market provides only brand $H$ under both regimes with the monopoly quantities. Hence, welfare levels are the same.

A4 $r_{1}<w_{L}-w_{H}<r_{2}$. The market is differentiated with uniform and linear pricing and non-differentiated with brand $H$ under perfect collusion. Calculations easily show that

$$
q_{L}(\hat{\beta})+q_{H}(\hat{\beta})-q_{H}^{C}=-\frac{2\left(\delta w_{L}-c\right)(2+\delta)+(\delta+3)\left(w_{L}-w_{H}\right)}{(4 \delta+9)(1+\delta)}<0
$$

As the social optimum includes only the high quality with $q_{H}^{*}>q_{H}^{C}$, it is immediate that $W^{U}<W^{C}$. 
A5 $w_{L}-w_{H} \geq r_{2}$. The two regimes are equivalent as they both induce a non-differentiated duopoly with brand $H$.

$\mathbf{B} \delta w_{L} \leq c<c_{0}$

Now we have $-(\delta-c)<r_{2}<r_{1} \leq c-\delta w_{L}$.

B1 $w_{L}-w_{H}<-(\delta-c)$. Equivalent to A1.

B2 $-(\delta-c)<w_{L}-w_{H}<r_{2}$. Equivalent to A2.

B3 $r_{2}<w_{L}-w_{H}<r_{1}$. We have a differentiated duopoly in the two regimes. Substitutions and manipulations yield

$W^{U}-W^{C}=\frac{\left(4(1+\delta)(\delta-c)-3\left(c-\delta w_{L}\right)+3(3+2 \delta)\left(w_{L}-w_{H}\right)\right)}{8 \delta(4 \delta+9)(1+\delta)}\left(c-\delta w_{L}-(3+2 \delta)\left(w_{L}-w_{H}\right)\right)$

which is a polynomial in $w_{L}-w_{H}$ of degree 2 with two roots

$$
\begin{aligned}
& r_{3}=\frac{4(1+\delta)(\delta-c)-3\left(c-\delta w_{L}\right)}{3(3+2 \delta)} \\
& r_{4}=\frac{c-\delta w_{L}}{3+2 \delta}
\end{aligned}
$$

Calculations easily show that $r_{3}<0<r_{4}<r_{1}$. But the ranking between $r_{3}$ and $r_{2}$ is ambiguous. We have $r_{3}<r_{2}$ if $c \in\left(\delta w_{L}, c_{1}\right)$ and $r_{3} \geq r_{2}$ if $c \in\left[c_{1}, c_{0}\right)$ with

$$
c_{1}=\delta \frac{8 \delta(\delta+2)+3 w_{L} \sqrt{4 \delta+9}(\sqrt{4 \delta+9}+2 \delta+3)}{8 \delta^{2}+28 \delta+27+3(2 \delta+3) \sqrt{4 \delta+9}}
$$

Moreover $W^{U}-W^{C}>0$ in the particular case where $w_{L}-w_{H}=0$. Therefore $W^{U}-W^{C}>0$ if $w_{L}-w_{H} \in\left(\max \left\{r_{2}, r_{3}\right\}, r_{4}\right)$ and negative otherwise. Note that $\max \left\{r_{2}, r_{3}\right\}<0$. 
B4 $r_{1}<w_{L}-w_{H}<c-\delta w_{L}$. Equivalent to A2.

B5 $w_{L}-w_{H} \geq c-\delta w_{L}$. Equivalent to A5.

$\mathbf{C} c_{0} \leq c<\delta$

Now we have $r_{2} \leq-(\delta-c)<r_{1}<c-\delta w_{L}$.

C1 $c \leq c_{0}$. Equivalent to A1.

C2 $c_{0}<c \leq-(\delta-c)$. We have a non-differentiated duopoly with brand $L$ under perfect collusion $\left(q_{L}^{C}=\left(1-w_{L}\right) / 2\right)$ whereas uniform and linear pricing induces a differentiated duopoly with quantities $q_{L}(\hat{\beta})$ and $q_{H}(\hat{\beta})$. Calculations show that $q_{L}^{C}>q_{L}^{U}+q_{L}^{C}$ if $w_{L}-w_{H}<$ $\left(c-\delta w_{L}\right) /(3 \delta+2)$, which is satisfied because $\left(c-\delta w_{L}\right) /(3 \delta+2)>-(\delta-c)$. As the social optimum is defined by $q_{L}^{*}=2 q_{L}^{C}$ and $q_{H}^{*}=0$, we necessarily have $W^{U}<W^{C}$.

C3 $-(\delta-c)<c \leq r_{1}$. The two regimes induce a differentiated duopoly as in B3. In B3 $W^{U}>W^{C}$ if $w_{L}-w_{H} \in\left(\max \left\{r_{2}, r_{3}\right\}, r_{4}\right)$. Here $\left(r_{3}, r_{4}\right) \subset\left(-(\delta-c), r_{1}\right)$. Therefore $W^{U}>W^{C}$ if $w_{L}-w_{H} \in\left(r_{3}, r_{4}\right)$.

C4 $r_{1}<c \leq c-\delta w_{L}$. Equivalent to A2.

C5 $c>c-\delta w_{L}$. Equivalent to A5. 